\title{
Changes in bronchoalveolar lavage fluid proteins in sarcoidosis: a proteomics approach
}

\author{
F. Sabounchi-Schütt*, J. Åström", U. Hellman", A. Eklund*, J. Grunewald*
}

Changes in bronchoalveolar lavage fluid proteins in sarcoidosis: a proteomics approach. F. Sabounchi-Schütt, J.Aström, U. Hellman, A. Eklund, J. Grunewald. (C)ERS Journals Ltd 2003.

ABSTRACT: In sarcoidosis, an inflammatory lung disease, the protein profile of bronchoalveolar lavage fluid (BALF) is altered. To study the BALF protein pattern changes in sarcoidosis, samples from six patients and four healthy individuals were analysed by two-dimensional polyacrylamide gel electrophoresis.

A comparison of the protein-spot patterns showed a significantly higher number of protein spots in the $\mathrm{pH}$ range 5.5-6.7 in patients compared to controls (472 versus 384$)$. Furthermore, the number of protein spots in the patients were significantly decreased in the acidic pH range 4.5-5.5 (399 versus 518). Measurement of the optical density in the gels showed varying expression levels for several protein spots. Seventeen of the altered protein spots were identified, of which seven have previously not been reported for BALF. Many of these are nonplasma proteins involved in the inflammatory and oxidant-antioxidant processes.

In conclusion, the bronchoalveolar lavage fluid protein content is altered in sarcoidosis patients, especially for proteins that are not derived from plasma. The described proteomics approach will in the future be used to asses overall changes in the protein content associated with sarcoidosis and may offer the possibility of identifying disease-specific proteins.

Eur Respir J 2003; 21: 414-420.
*Dept of Medicine, Karolinska Institute, Division of Respiratory Medicine, Lung Research Laboratory, Karolinska Hospital, Stockholm, and ${ }^{\#}$ Amersham Biosciences and ${ }^{\prime}$ Ludwig Institute for Cancer Research, Uppsala, Sweden.

Correspondence: F. Sabounchi-Schütt, Karolinska Institutet, Dept of Medicine, Division of Respiratory Medicine, Lung Research Laboratory, L4:0, Karolinska Hospital, SE-171 76 Stockholm, Sweden.

Keywords: Bronchoalveolar lavage fluid, matrix-assisted laser desorption/ionisation time of flight mass spectrometry, protein quantitation, protein-spot pattern, sarcoidosis, two-dimensional polyacrylamide gel electrophoresis

Received: July 92002

Accepted after revision: November 29 2002

This study was supported by the Swedish Medical Research Council (K2002-74X14182-01A), The Swedish Heart-Lung Foundation, the King Oscar II Jubilee Foundation and Karolinska Institutet.
Sarcoidosis is a systemic granulomatous disease that primarily affects the lungs and the lymphatic system. The cause of the disorder is still unknown. However, since sarcoidosis was first described, much progress has been made in terms of understanding the clinical and unique immunological and pathological features of the disorder. Less is known about the protein specificity and different variants of the proteins, which may contribute to the development and expression of the disease. A classic tool for studying epithelial lining fluid (ELF) proteins is bronchoscopy with lung lavage. Sampling ELF by bronchoalveolar lavage (BAL) has permitted the recovery of airway alveolar space cells and soluble substances in the extracellular lining fluid, which have been used both diagnostically and as research materials. The retrieval of soluble substances and secretory proteins via BAL has contributed to the understanding of the pathogenesis of sarcoidosis and other inflammatory lung disorders [1-3]. Numerous studies have described the cellular components of the BAL fluid (BALF) in sarcoidosis $[1,4,5]$. However, the overall distribution of the proteins in human BALF is still not well known.

Recent studies on BALF suggest that two-dimensional polyacrylamide gel electrophoresis (2-D PAGE) may be useful for investigation of changes in protein expression of patients with different lung diseases [6-9]. It is a powerful method capable of displaying the protein distribution in an organ without the requirement of detailed knowledge of individual proteins. This method enables protein separation from complex biological samples, such as BALF, resulting in a single gel with a hundred to thousands of protein spots resolved in it. The current authors have previously reported the detection and identification of BALF-specific proteins from healthy individuals [10]. The goal of the current study was to establish an overall pattern of soluble BALF proteins in sarcoidosis and to investigate any changes in protein expression associated with this disease. To do this 2-D PAGE in combination with narrow-range $\mathrm{pH}$ gradients has been used. The narrow-range $\mathrm{pH}$ gradients maximises the resolving power, thereby reducing the number of co-migrating protein spots and facilitates the subsequent identification procedure by peptide-mass fingerprinting using mass spectrometry (MS). In order to improve the detection of low-abundance proteins and to enable protein identification, the recently developed paper bridge loading method [11] was used. Six sarcoidosis patients with common clinical features, i.e. Löfgren's syndrome [12], and four healthy controls were included in this study. Besides a detailed characterisation of the BALF proteins in these individuals, total and differential cell counts were also performed.

\section{Materials and methods}

\section{Study population}

BALF from six patients with sarcoidosis and four healthy individuals was investigated. All individuals were recruited 
from the Dept of Medicine, Karolinska Hospital (Stockholm, Sweden) with the approval of the ethical committee and informed consent from the patients and the healthy individuals. All patients had an acute onset of sarcoidosis with Löfgren's syndrome [12], including bilateral hilar lymphadenopathy, fever, ankle arthralgia and/or erythema nodosum, i.e. a clinical picture strongly in support of the diagnosis. Furthermore, all patients had an elevated CD4/CD8 BALF ratio (table 1) in accordance with the diagnosis and three of them had in addition a positive biopsy (patient nos. 3, 4 and 5). The healthy individuals had normal chest radiography and were without any signs of respiratory diseases and other inflammatory or infectious disorders.

\section{Sample preparation}

Bronchoscopy with BALF was performed as previously described [13]. Briefly, under local anaesthesia, the flexible fibreoptic bronchus (Olympus Optical Co. Ltd, Tokoyo, Japan) was wedged in the right middle lobe bronchoscope and five aliquots of $50 \mathrm{~mL}$ sterile $37^{\circ} \mathrm{C}$ buffered saline was instilled. The fluid was gently aspirated after each aliquot, collected in a sterile siliconised bottle and kept on ice. The lavage was then filtered through a single layer of Dacron net type AP32 (Millipore, Sundbyberg, Sweden) and cells were separated by centrifugation at $400 \times g$ for $10 \mathrm{~min}$ at $4{ }^{\circ} \mathrm{C}$. The cell pellet underwent cytospin centrifugation at $500 \times g$ for 3 min (Cytospin 2; Shandon, Runcorn, UK) followed by manual differential counting of cells after staining with MayGrünwald and Giemsa solution. The BALF supernatant was kept on ice and stored at $-80^{\circ} \mathrm{C}$ until used. The BALF was thawed and the protein concentration was determined using a protein assay kit, based on the method described by BRADFORD [14] with bovine serum albumin as the reference. In order to concentrate the proteins, remove salt and low molecular-weight components, the fluid was applied to an Oasis HLB extraction cartridge (Waters Co., Milford, MA, USA), equilibrated with $0.1 \%$ trifluoroacetic acid (TFA). After washing the cartridge with $10 \%$ acetonitrile (ACN), $0.1 \%$ TFA, the proteins were eluted in $80 \%$ ACN, $0.1 \%$ TFA. The eluted protein was evaporated to dryness using a vacuum centrifuge (Savant Speed-Vac concentrator; Thermo Electron Corporation, Waltham, MA, USA). In order to equalise the amount of the total protein used, each BALF sample after preparation and lyophilisation was weighed and exactly the same amount in $\mathrm{g}$ was loaded for the first dimension separation of each sample. For each experiment (analytical) the same amount $(20-40 \mu \mathrm{g})$ was used. The variation of $20-40 \mu \mathrm{g}$ was dependent on the $\mathrm{pH}$ interval used, but an equal amount was used for every comparison in the different $\mathrm{pH}$ intervals. A higher amount of protein $(2 \mathrm{mg}$ ) was loaded for the mass spectrometry identification experiments. The protein pellet was resuspended in a solution containing $8 \mathrm{M}$ urea, $4 \%$ 3[(3-cholaminopropyl) diethylamonio]-1-propane sulphonate (CHAPS), $65 \mathrm{mM}$ dithiothreitol (DTT), and $2 \%$ of the $3-10$ nonlinear immobilised $\mathrm{pH}$ gradient (IPG) buffer, to the desired concentration.

\section{Two-dimensional electrophoresis}

Immobilised dry strips (Amersham Biosciences, Uppsala, Sweden) pH 3-7, 4-7, 6-9, 5.5-6.7 and 4.5-5.5 18-cm long were rehydrated overnight at room temperature in a solution containing $8 \mathrm{M}$ urea, $2 \%$ CHAPS, $1 \%$ of the related IPGbuffer, $18 \mathrm{mM}$ DTT and a trace of bromophenol blue. The sample was applied in a volume of $60 \mu \mathrm{L}(20-40 \mu \mathrm{g})$ using cup at the anodic end of the strips. The proteins were focused on electrophoresis units, at $19^{\circ} \mathrm{C}$, using a one-step linear voltage gradient increasing from $300-3,500 \mathrm{~V}$ in $2 \mathrm{~h}$, the voltage was then kept constant at 3,500 $\mathrm{V}$ for an additional $18 \mathrm{~h}$, giving a total of $65 \mathrm{kVh}$. The strips were equilibrated for $15 \mathrm{~min}$ in $19 \mathrm{mM}$ DTT, $50 \mathrm{mM}$ tris, $6 \mathrm{M}$ urea, $30 \%$ glycerol, $2 \%$ sodium dodecylsulphate, and then for $15 \mathrm{~min}$ in the same solution except that DTT was replaced by $0.2 \mathrm{M}$ iodoacetamide. The second-dimension separations were performed as described previously [10]. The gels were silver stained with automated silver staining equipment. The method for staining was as previously reported [15]. Briefly, after fixation with acid and sensitisation with sodium thiosulphate in alcoholic sodium acetate, the gels were impregnated with silver nitrate and developed by reduction of silver ion using sodium carbonate solution containing formaldehyde. For the micropreparative experiments $2 \mathrm{mg}$ BALF proteins were separated using the cup loading or the recently developed paper bridge application method [11]. Briefly, $0.5 \mathrm{~mL}$ sample solution was added to a thick filter paper. The filter paper was positioned as a bridge between the acidic end of the IPG strip and the corresponding electrode. The proteins were focused on the electrophoresis unit for a total of $100 \mathrm{kVh}$. After seconddimension separation the gels were stained with Coomassie brilliant blue $\mathrm{R} 250$. The stained second-dimension gels were scanned in an ImageScanner ${ }^{\mathrm{TM}}$ (Amersham Biosciences). Parallel experiments were performed for each $\mathrm{pH}$ gradient. The analytical gel figures are composites of two parallel experiments from each subject; $13 \mathrm{~cm}$ in the focusing direction from one gel and $5 \mathrm{~cm}$ from the other. The region of overlap has been removed and the point of assembly is visible.

Table 1.-Summary of the individual characteristics of the 10 individuals included in this study

\begin{tabular}{|c|c|c|c|c|c|c|c|c|c|c|}
\hline & \multicolumn{6}{|c|}{ Patients } & \multicolumn{4}{|c|}{ Healthy controls } \\
\hline & 1 & 2 & 3 & 4 & 5 & 6 & 7 & 8 & 9 & 10 \\
\hline Age yrs & 31 & 32 & 25 & 37 & 40 & 39 & 28 & 24 & 49 & 25 \\
\hline Sex & $\mathrm{M}$ & M & $\mathrm{F}$ & M & M & M & $\mathrm{F}$ & M & $\mathrm{M}$ & M \\
\hline Smoking & Ex & Ex & No & No & No & No & No & No & No & No \\
\hline Radiographical stage & I & I & I & I & II & II & 0 & 0 & 0 & 0 \\
\hline Cell concentration $\times 10^{6} \mathrm{~L}^{-1}$ & 192 & 146 & 164 & 296 & 393 & 400 & 89 & 60 & 134 & 122 \\
\hline CD4/CD8 ratio & 14 & 4.2 & 8.0 & 9.8 & 11 & 8.0 & 3.3 & 0.9 & ND & 1.6 \\
\hline \multicolumn{11}{|l|}{ BAL cell differential counts $\%$} \\
\hline Alveolar macrophages & 98 & 87 & 86 & 51 & 51 & 53 & 96 & 84 & 98 & 92 \\
\hline Lymphocytes & 2.2 & 13 & 13 & 46 & 49 & 46 & 2.8 & 15 & 1.6 & 6.2 \\
\hline Neutrophils & 0.2 & 0.4 & 1.4 & 2.0 & 0.6 & 0.2 & 0.4 & 0.8 & 0.4 & 1.2 \\
\hline BALF protein concentration $\mu \mathrm{g} \cdot \mathrm{mL}^{-1}$ & 136 & 168 & 124 & 98 & 198 & 131 & 80 & 72 & 64 & 51 \\
\hline
\end{tabular}

BAL: bronchoalveolar lavage; BALF: bronchoalveolar lavage fluid; M: male; F: female; Ex: exsmoker; No: nonsmoker; ND: no data. 


\section{Evaluation of the gel images}

The resulting gels were analysed using ImageMaster 2-D software version 3.01 (Amersham Biosciences) with a computerised 8-bit system and freshly calibrated. The typical analysis parameters for automatic spot detection were as follows: sensitivity was set to 9,636 , operator size to 73 , noise factor to 5, background factor to 68 and split level to 7 . The gels were manually edited. Since all gel images contain levels of background intensity inherent in the scanned image, the background was subtracted by the mode of nonspots for the accurate spot measurements. To measure the optical density (OD) of the protein spots detected in the silver stained gels the volume of each spot was divided by the total volume of all of the spots of the same gel. Since this method of normalisation tends to produce extremely small values, the result was multiplied by a scaling factor of 100 , which produces spot percentage volume. This volume per cent is dependent on the saturation of the spots with respect to the staining differences. The software was set to not generate autoseeds (i.e. spots common on both gels), but to allow for positioning of user seeds. In order to detect differentially expressed protein spots in the different gels, by instruction, the software created one map containing all spots detected in the four gels of the healthy controls and presented this as a "reference map". The software used this reference map only as a start point for the comparison between patients and the controls. For detailed comparisons between individual patients and controls, the individual gels of the patients were subsequently compared to each individual control gel (four gels). Only those spots that were reproducibly different in the patients compared to all the controls were considered. The total number of spots, nonmatched spots and the normalised volume percentage expressed in OD value were then calculated for each gel. The spots that differed with $\geqslant 50 \%$ in intensity and those not matched to the control gels were then highlighted and inspected carefully for inappropriate matching, staining artifacts or bad spot detection.

\section{Protein identification}

The selected gel plugs were punched out from the Coomassie stained gels. Removal of salts and staining residues was performed as described previously [10]. The gel pieces were then dried under vacuum and rehydrated in a solution containing $5 \mu \mathrm{L}$ trypsin $(0.3 \mu \mathrm{g})$ overnight at $30^{\circ} \mathrm{C}$. The generated peptides were extracted, using $100 \mu \mathrm{L}$ of $50 \% \mathrm{ACN}, 0.45 \%$ TFA and incubated twice at $30^{\circ} \mathrm{C}$ for $1 \mathrm{~h}$. The pooled extracts were then lyophilised for $2 \mathrm{~h}$. The lyophilised sample was dissolved in $5 \mu \mathrm{L}$ of matrix (a saturated solution of $\alpha$-cyano4-hydroxy-cinnamic acid, (Fluka, Cork, Ireland) in 50\% ACN, $0.45 \%$ TFA containing reference peptides, ${ }^{\text {ile }}$ angiotensin III, human adrenocorticotropin 18-39 (Sigma, Cork, Ireland). Finally, $1 \mu \mathrm{L}$ was applied onto the target slide using the dried droplet method [16]. For low concentration peptides ZipTip clean-up (Millipore) was used according to the manufacturer's instruction. Mass spectra were acquired using matrix-assisted laser desorption/ionisation time of flight (MALDI-ToF) mass spectrometers, Ettan MALDI-ToF (Amersham Biosciences) or Bruker Autoflex (Bruker Daltonics, Bremen, Germany) as described previously [17]. The spectra were calibrated using the internal reference peptides or trypsin autodigestion peaks. Trypsin autodigestion peaks and internal reference peptides were excluded from the database searching. The search program proFound version 4.10.4 was used for peptide mass fingerprinting [18]. The parameters for the searches were as follows: species of origin, all taxa or Homo sapiens; molecular range set to 5-3,000 kDa; isoelectric point (pI) range from 1-14; and digestion by trypsin allowing for no more than one missed cut. Monoisotopic peptide masses were used and the mass tolerance error was set up to $0.1-0.2 \mathrm{Da}$. Cysteine was considered as carboxyamidomethyl cysteine and partial modification of methionine by oxidation was allowed. The first listed sequence entry of the top protein candidate is shown in table 2. Spot identifications giving a $\mathrm{Z}$ score (a statistical value of the quality and the reliability of the search

Table 2. - Summary of the bronchoalveolar lavage fluid proteins from $\mathrm{pH}$ ranges 4.5-5.5 and 5.5-6.7 identified using matrixassisted laser desorption/ionisation time of flight mass spectrometry and peptide mass fingerprinting

\begin{tabular}{|c|c|c|c|c|c|}
\hline Spot no. ${ }^{\#}$ & Protein name & Database i.d. & Score $\mathrm{Z}$ value ${ }^{+}$ & Coverage $\% §$ & OD intensity in patients \\
\hline 1 & Not determined & & & & Increased* \\
\hline 2 & Monocyte/neutrophil elastase inhibitor & Gi 266344 & 1.50 & 19 & Decreased* \\
\hline 3 & Unknown & & & & Decreased $* *$ \\
\hline 4 & Calcyphosine & Gi 4757908 & 2.30 & 52 & Decreased* \\
\hline 5 & Glutathione $S$-transferase, chain A & Gi 11514451 & 2.19 & 62 & Decreased $* *$ \\
\hline 6 & Thioredoxin & Gi 230939 & 0.91 & 35 & Decreased \\
\hline 7 & Immunoglobulin $\kappa$ light chain & Gi 2894829 & 1.48 & 40 & Increased* \\
\hline 8 & Human $\beta_{2}$ glycoprotein I & Gi 6435718 & 2.29 & 18 & Increased \\
\hline 9 & Unknown & & & & Increased $* *$ \\
\hline 10 & Clara cell & Gi 256397 & 0.80 & 19 & Increased \\
\hline 11 & $\beta$-galactosidase binding lectin & Gi 4504981 & 1.14 & 45 & Decreased** \\
\hline 12 & Aldehyde dehydrogenase 1 & Gi 4502031 & 0.78 & 14 & Decreased* \\
\hline 13 & Cathepsin $\mathrm{H}$ & Gi 29708 & 0.77 & 17 & Decreased* \\
\hline 14 & Annexin I & Gi 4502101 & 2.31 & 29 & Decreased $* *$ \\
\hline 15 & Antioxidant protein II & Gi 4758638 & 2.41 & 48 & Decreased $* *$ \\
\hline 16 & Fatty acid binding protein & Gi 119781 & 2.40 & 69 & Decreased $^{* *}$ \\
\hline 17 & Calgizzarin & Gi 5032057 & 1.10 & 41 & Decreased* \\
\hline 18 & Not determined & & & & Decreased* \\
\hline 19 & Heat shock $27 \mathrm{kd}$ protein 1 & Gi 4504517 & 2.38 & 47 & Increased \\
\hline 20 & Aldehyde reductase & Gi 1633300 & 2.30 & 31 & Decreased \\
\hline 21 & $\beta_{2}$-microglobulin & Gi 195503 & 2.14 & 60 & Increased \\
\hline
\end{tabular}

OD: optical density. ${ }^{\#}$ : spot no. refers to the annotation in figures $1 \mathrm{a}$ and $\mathrm{b}$; ${ }^{\top}$ : National Center for Biotechnology Information $(\mathrm{NCBI}) ;{ }^{+}$: score $\mathrm{Z}$ value shows the quality of database search results; ${ }^{\S}$ : sequence coverage refers to the observed sequence coverage of the assigned protein. *: $\mathrm{p}<0.05$, from the comparison of the six patients and four healthy controls; $* *$ : $\mathrm{p}<0.01$, from the comparison of the six patients and four healthy controls. 
result [18]) $<0.5$ in the table are marked as "not determined", since their identifications were regarded to be uncertain.

\section{Statistical methods}

To be regarded as differentially expressed, only protein spots with OD values that differed by $>50 \%$ in at least five of the six patients compared to the reference map were considered. All OD values of differentially expressed protein spots of individual patients were thereafter compared to all the corresponding control values. Differences between patients and controls were tested using the nonparametric Mann-Whitney U-test and a $\mathrm{p}<0.05$ was considered significant. Results are presented as median with p25 and p75 values (tables 1 and 3 ) as the range.

\section{Results}

\section{Characteristics of the investigated individuals}

Individual characteristics and the results of the differential cell counts of the 10 BALF samples included in this study are shown in table 1. Patients BALF compared to control samples generally contained a higher concentration of cells, more relative numbers of lymphocytes and significantly elevated CD4/CD8 ratios. The total protein concentration in BALF was significantly elevated $(\mathrm{p}<0.01)$ in the patients (median $134 \mu \mathrm{g} \cdot \mathrm{mL}^{-1}$ (range $\left.124-168\right)$ ) compared to controls $\left(68.0 \mu \mathrm{g} \cdot \mathrm{mL}^{-1}\right.$ $(57.5-76.0))$.

Bronchoalveolar lavage fluid protein-spots patterns differ in sarcoidosis patients compared to healthy individuals

To investigate the protein expression pattern in the disease states of human BALF, 2-D (PAGE) separations were run. Initially, wide ranging $\mathrm{pH}$ gradients $3-7,6-9$ and 4-7 were used for separation of BALF proteins in the first dimension. For each $\mathrm{pH}$ interval at least two parallel experiments were performed. From the 2-D protein patterns obtained, a high number of protein spots in the $\mathrm{pH}$ region 4.5-6.7 were distinguished, approximately one-fifth of the spots were found in the $\mathrm{pH}$ region $6-9$, while only a limited number of spots were detected below pH 4.0 (data not shown). This was in agreement with a previous report on the spot distribution in the normal BALF map [10]. Based on these observations the authors decided to focus the proteomics BALF investigation on the $\mathrm{pH}$ interval 4.5-6.7, using narrow range IPG strips 4.5-5.5 and 5.5-6.7. Representative examples of BALF protein gels in these $\mathrm{pH}$ regions from sarcoidosis patients are shown in figure 1 .

Table 3.- The number of protein spots detected by twodimensional polyacrylamide gel electrophoresis separation of bronchoalveolar lavage fluid from the patients and the healthy control in the $\mathrm{pH}$-interval 4.5-5.5, 5.5-6.7, and in the combined $\mathrm{pH}$ interval 4.5-6.7

\begin{tabular}{|c|c|c|c|c|c|c|c|c|c|c|}
\hline & \multicolumn{6}{|c|}{ Patients } & \multicolumn{4}{|c|}{ Healthy controls } \\
\hline & 1 & 2 & 3 & 4 & 5 & 6 & 7 & 8 & 9 & 10 \\
\hline pH 4.5-5.5 & 464 & 407 & 392 & 329 & 418 & 359 & 517 & 454 & 550 & 577 \\
\hline pH 5.5-6.7 & 491 & 440 & 778 & 411 & 453 & 615 & 367 & 296 & 430 & 402 \\
\hline pH 4.5-6.7 & 955 & 847 & 1170 & 740 & 871 & 974 & 884 & 750 & 980 & 979 \\
\hline
\end{tabular}

In figure $1 \mathrm{a}$ region of heavy staining can be seen in the $\mathrm{pH}$ region 5.5-5.8, which corresponds to the migration of albumin in the gels. Several of the detected protein spots have previously been identified and characterised (fig. 1, [10]).

In the control BALF, more protein spots appeared in the acidic $\mathrm{pH}$ range $4.5-5.5$ compared to the $\mathrm{pH}$ interval 5.5-6.7, while in the patient BALF such a trend was not obvious (table 3 ). There were significantly more spots in the $\mathrm{pH}$ range 5.5-6.7 in the patient compared to controls (472 (440-625) versus $384(331-416) ; \mathrm{p}<0.05)$, while in the acidic $\mathrm{pH}$ interval $4.5-5.5$ the number of spots were significantly decreased in the patients samples (399 (359-418) versus 518 (485-598); $\mathrm{p}<0.05)$ (table 3).

Variation of the protein expression level in patients versus controls

To quantify the protein expression level, differences between patient and control 2-D gels were carefully inspected. Spots that reproducibly differed in intensity, and for which a reliable OD could be calculated, were selected for further

a)

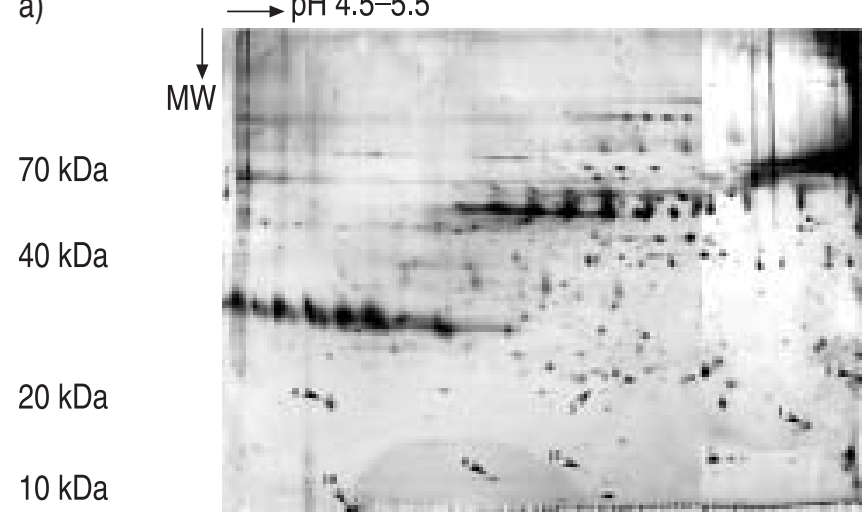

b)

$70 \mathrm{kDa}$

$40 \mathrm{kDa}$

$20 \mathrm{kDa}$

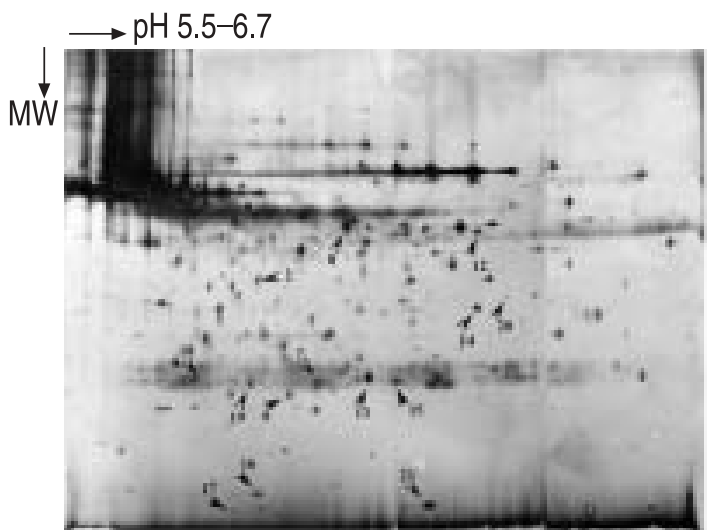

$10 \mathrm{kDa}$

Fig. 1. - The two-dimensional protein-spot pattern of sarcoidosis bronchoalveolar lavage fluid (BALF) in the $\mathrm{pH}$ interval a) 4.5-5.5 (patient 2) and b) 5.5-6.7 (patient 5). A $30 \mu \mathrm{g}$ BALF sample was separated in immobilised $\mathrm{pH}$ gradient $4.5-5.5$ or 5.5-6.7 strips. The second dimension separation was run using 9-18\% gradient sodium dodecylsulphatepolyacrylamide gel electrophoresis. The resulting protein patterns were visualised using silver staining. Arrows indicate identified proteins altered in the patients. The numbers refer to the identification of the proteins presented in table 3 . Since a second dimension gel is only $13-\mathrm{cm}$ wide and the strips of the first dimension are $18 \mathrm{~cm}$, the gel images are composites of two parallel experiments from the same patient, where $13 \mathrm{~cm}$ in the focusing direction is from one gel and $5 \mathrm{~cm}$ from the other. The region of overlap has been removed and the point of assembly is visible. 

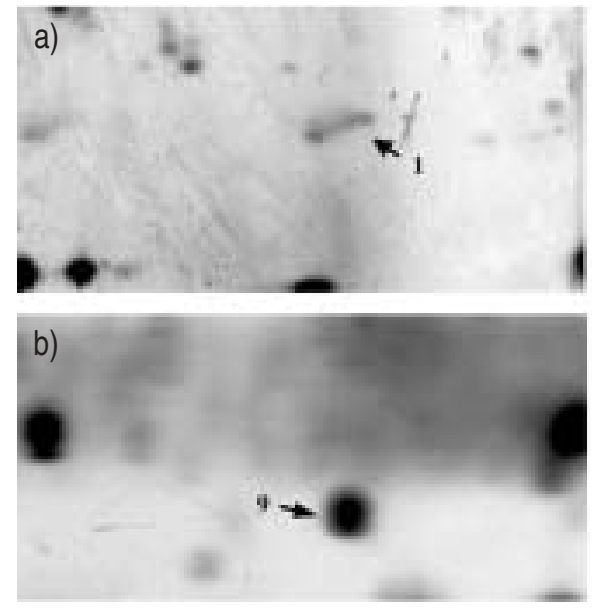
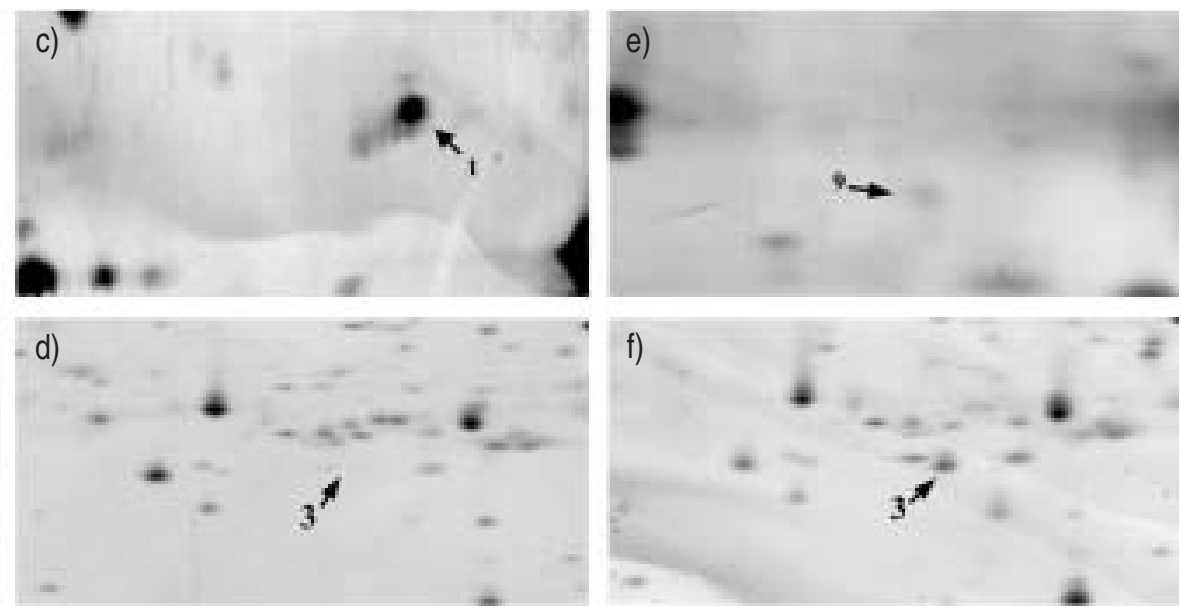

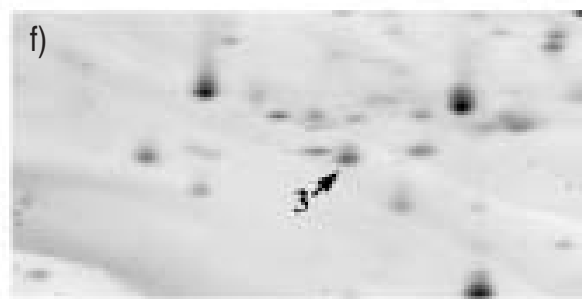

Fig. 2. - Enlarged regions of the two-dimensional gel images of bronchoalveolar lavage fluid (BALF) samples showing protein spots 1 (a, c), 9 (b, e) and $3(d, f)$. a), d) and e) show the pattern in healthy controls while b), c) and f) show the same region in the sarcoidosis BALF. The spots are indicated by arrows and the numbers refer to the identification of the proteins presented in figure 1 and table 3 .

analysis. For each of these spots at least two independent OD measurements were obtained in the same $\mathrm{pH}$ interval, and in most cases additional OD values were acquired from overlapping (wide or narrow range) $\mathrm{pH}$ intervals. In total, 21 spots were found to differ between patients and controls (annotated in fig. 1). In figure 2 typical spot pattern variations are highlighted, showing qualitative differences between controls and patients.

Fifteen of the altered protein spots differed significantly. The OD values for these proteins are shown in figures $3 \mathrm{a}$ and b. Of the 21 altered protein spots in the patients, fourteen were decreased and seven were increased in intensities compared to the healthy controls. In the $\mathrm{pH}$ range 5.5-6.7 fourteen protein spots were changed, among them nine were decreased while five were increased in intensity, compared to the controls. Seven of the altered protein spots were in the $\mathrm{pH}$ range 4.5-5.5, three of five were decreased and two were increased. Sixteen of the altered protein spots had molecular weights between $10-25 \mathrm{kDa}$ and 12 of these were decreased in intensity.

\section{Identification of proteins in bronchoalveolar lavage fluid}

In order to identify the altered proteins in the patients, all the 21 protein-spots were subjected to MALDI ToF MS. Seventeen of these proteins could be identified (table 2). Figures 1a and $\mathrm{b}$ show the location of these proteins in the 2-D maps of the sarcoidosis patients. Seven of the identified proteins have, to the best of the authors' knowledge, not previously been recognised in published BALF 2-D maps: monocyte neutrophil elastase inhibitor (spot 2), calcyphosine (spot 4), $\beta$-galactosidase binding lectin (spot 11), aldehyde dehydrogenase I (spot 12), cathepsin H (spot 13), antioxidant protein II (spot 15) and aldehyde reductase (spot 20). The positions of spots 5, 11 and 12 have, in addition, been verified against the spot positions found in other 2-D maps [19, 20]. Two proteins (spot 3 and 9) were assigned as unknown by the database. Spots 1 and 18 were marked as "not determined" in table 2, since their spot identifications gave a $\mathrm{Z}$ score $<0.5$, indicating uncertain identifications.

\section{Discussion}

The patients included in this study were chosen according to their diagnosis of acute sarcoidosis with Löfgren's syndrome. This group is characterised by similarities in their clinical features and in their immunological response [12, 21, 22]. The BALF cellular composition of these patients showed,
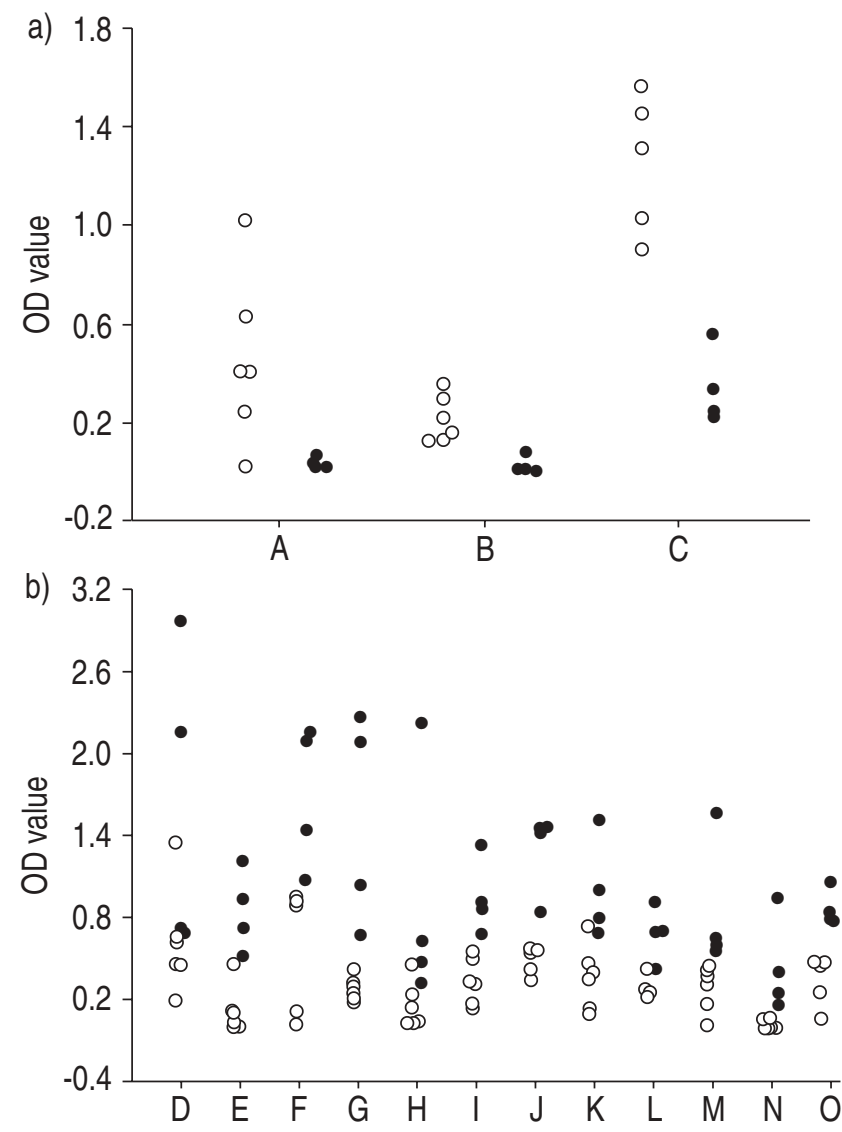

Fig. 3.-Optimal density (OD) values of proteins a) upregulated and b) downregulated in the patients. A: unknown identity; B: not determined; B and C: immunoglobulin $\kappa$ light chain; D: (calcyphosine); E: $\beta$-galactosidase binding lectin; F: cathepsin H; G: fatty acid binding protein; H: calgizarrin; I: glutathione $S$-transferase; J: antioxidant proteins II; K: aldehyde dehydrogenase I; L: neutrophil elastase inhibitor; $\mathrm{M}$ : annexin I; N: not determined; $\mathrm{O}$ : unknown identity. D-H were grouped as proteins involved in cell-cell interactions and proliferation processes. $\mathrm{I}-\mathrm{K}$ as proteins involved in oxidation, antioxidatory processes. L, M as proteins involved in antiinflammatory processes. $\mathrm{N}$ and $\mathrm{O}$ are unknown. $\bigcirc$ : patients; controls. All differences were statistically significant $(\mathrm{p}<0.05)$. 
as expected, an increased CD4/CD8 ratio [23] and an increase of the relative number of lymphocytes. Although the total number of protein spots in BALF of the patients was approximately equal to that of the healthy controls, the total protein concentration was significantly increased. This could be due to an increase of some plasma proteins in BALF of sarcoidosis in agreement with some published reports [9, 24]. An increase of a few individual proteins would influence the total protein concentration in the samples but not necessarily affect the number of the protein spots detected in a 2-D gel. An overview of BALF protein alterations in different lung diseases has been difficult to obtain since the BAL technique produces considerable dilution of proteins and a very high salt content in the retrieved fluid. The composition of BALF proteins may also vary in different levels of the respiratory tract. Furthermore, many proteins in BALF are either present at a low concentration or co-immigrate during the electrophoresis focusing. Here, an overview of the total protein distribution of six sarcoidosis patients with distinct clinical similarities in the $\mathrm{pH}$ interval 4.5-6.7 is presented. Narrow-range $\mathrm{pH}$ gradients were used, which allowed a higher sample load, thereby enabling the detection of more protein spots and isoforms than with previously used wide range $\mathrm{pH}$ gradients. The paper bridge sample application method was also used [11], which allowed for the use of high sample load, the detection of low-abundance proteins, the separation of high molecular-weight proteins and improved spot resolution. This approach allowed for the detection and identification of seven proteins, which previously have not been reported in the available 2-D maps of BALF.

The overall protein composition in the sarcoidosis map shows a high rate of similarity to the corresponding control map. As in the control maps, most of the protein spots appear in $\mathrm{pH}$ interval 4.5-6.7. However, in patients, the number of proteins in the $\mathrm{pH}$ interval 5.5-6.7 were significantly elevated compared to the same region in the control samples, suggesting that many of the disease-related proteins could be found in this $\mathrm{pH}$ interval. In accordance with this, fourteen of 21 altered protein spots were in this $\mathrm{pH}$ interval. In the more acidic region of the sarcoidosis gel, the number of spots decreased significantly compared to the control gel. Interestingly, all of the altered proteins identified in this region were nonplasma proteins, restricted to BALF.

To be able to calculate a reliable OD value for quantitative comparisons, identical samples from the same individual were run several times with different IPGs in the first dimension separation. In addition, parallel experiments with samples from both patients and controls were performed. Moreover, the variability in the silver staining of 2-D gels has been considered through a normalisation of the spot patterns in each gel, before the matching procedure. However, due to 2-D PAGE limitations, the characterisation of all protein spots, which apparently differed in intensity in the present experiments, was not possible, e.g. extreme high or low-abounded proteins. Such protein spots either gave an uncertain OD value or had a very low concentration and were absent in the Coomassie gels and therefore could not be subjected to MS.

As many as 12 proteins were significantly decreased in intensity in the patients compared to healthy controls. These proteins included antioxidant proteins. Antioxidant proteins can be expected to provide an initial defence against inhaled toxins, and are also a part of the host defence against a wide range of organisms and may be consumed during the acute sarcoidosis inflammation. The decreased level of these proteins in the patients could be an indicator of imbalance of oxidant/ antioxidants in this disease. Furthermore, two proteins identified in this study also involved in oxidative activities (aldehyde dehydrogenase I and aldehyde reductase, which are functionally and structurally related enzymes) were found to be decreased in the sarcoidosis patients.
Lower respiratory tract secretion contains neutrophil elastase [25]. One of the newly identified proteins presented in this work is neutrophil elastase inhibitor (NEI), which regulates the activity of neutrophil elastase, as well as protease, cathepsin $\mathrm{G}$ and proteinase. The likely role of NEI is to regulate protease activity and prevent tissue damage by phagocytic cells $[26,27]$. Thus NEI-mediated defence against free NE in the lower respiratory tract is significantly decreased in sarcoidosis. The reduced level of annexin I could also reflect the NEI-mediated defence against free $\mathrm{NE}$ in the patients. Annexin I, normally present at high concentration on the epithelial surface of the normal lung and in BALF, has potent anti-inflammatory activity [28]. Degradation of this protein has been observed in BALF from patients with various lung diseases $[29,30]$. This degradation has also been suggested to be mediated by neutrophil elastase in ELF [31, 32], suggesting a possible link between annexin I and NEI.

Among the decreased proteins in BALF of the patients, a calcyphosine was found, which is involved in cell growth and differentiation and may regulate essential cell functions like proliferation and differentiation as well as cell degranulation [33]. Decreased levels of this protein might cause inhibition of these processes.

A few studies have been performed on human total BALF proteins in sarcoidosis using proteomics [9, 34, 35]. Only one of these studies directly compared BALF of sarcoidosis patients to that of healthy controls [9]. Previous studies have instead focused on establishing and updating the human BALF protein map. WATTIEZ et al. [9] reported several proteins to differ in expression in sarcoidosis compared to healthy controls. Although a few of these proteins were also recognised in the present study (i.e. $\beta_{2}$-microglobulin and clara cell protein), the majority of the differently expressed proteins identified were not the same. Different experimental conditions, such as using the narrow-range $\mathrm{pH}$ gradients for the first dimension separation in this study, precluded any exact comparison to their results and may have been misleading. In this study, an overview of BALF proteins in sarcoidosis is shown and the alteration of 21 silver-stained protein spots is reported; 17 could be identified. Twelve of the 17 identified proteins were significantly reduced in the patients. An increase in the plasma protein level in the patients in the $\mathrm{pH}$ interval used was not observed. The majority of the identified proteins were rather acidic $(4.5<\mathrm{pI}<6.7)$ had low molecular weights $(<30 \mathrm{kD})$ and did not originate from plasma. Furthermore, seven new nonplasma proteins, not reported previously for BALF 2-D maps, are presented. Proteins from two spots did not match with any known protein and were assigned as unknown. Consistent with the effect of the inflammatory processes some of the altered proteins observed in this report are involved in oxidative, anti-inflammatory processes and in the regulation of a variety of cellular processes related to proliferation. However, the exact extracellular role of some identified proteins in this work are presently unknown.

The proteomics approach used in this study will contribute to the characterisation of protein patterns, allow for the assessment of overall changes in the protein content associated with different lung diseases and also for the detection and identification of proteins in bronchoalveolar lavage fluid that might be used as disease-specific markers.

\footnotetext{
Acknowledgements. The authors would like to thank B. Bjellqvist for interpretation of the 2-D analyses. They would also like to thank S. Gripenbäck for help with 2-D experiments and A-C. Bergman for discussion concerning mass spectrometry analyses.
} 


\section{References}

1. Merrill W, O'Hearn E, Rankin J, Naegel G, Matthay RA, Reynolds HY. Kinetic analysis of respiratory tract proteins recovered during a sequential lavage protocol. Am Rev Respir Dis 1982; 126: 617-620.

2. Merrill WW, Goodenberger D, Strober W, Matthay RA, Naegel GP, Reynolds HY. Free secretory component and other proteins in human lung lavage. Am Rev Respir Dis 1980; 122: 156-161.

3. Reynolds HY, Fulmer JD, Kazmierowski JA, Roberts WC, Frank MM, Crystal RG. Analysis of cellular and protein content of broncho-alveolar lavage fluid from patients with idiopathic pulmonary fibrosis and chronic hypersensitivity pneumonitis. J Clin Invest 1977; 59: 165-175.

4. Reynolds HY. Use of bronchoalveolar lavage in humans-past necessity and future imperative. Lung 2000; 178: 271-293.

5. Merchant RK, Schwartz DA, Helmers RA, Dayton CS, Hunninghake GW. Bronchoalveolar lavage cellularity. The distribution in normal volunteers. Am Rev Respir Dis 1992; 146: $448-453$.

6. Lindahl M, Stahlbom B, Tagesson C. Two-dimensional gel electrophoresis of nasal and bronchoalveolar lavage fluids after occupational exposure. Electrophoresis 1995; 16: 11991204.

7. Lindahl M, Svartz J, Tagesson C. Demonstration of different forms of the anti-inflammatory proteins lipocortin-1 and clara cell protein-16 in human nasal and bronchoalveolar lavage fluids. Electrophoresis 1999; 20: 881-890.

8. von Bredow C, Birrer P, Griese M. Surfactant protein A and other bronchoalveolar lavage fluid proteins are altered in cystic fibrosis. Eur Respir J 2001; 17: 716-722.

9. Wattiez R, Hermans C, Cruyt C, Bernard A, Falmagne P. Human bronchoalveolar lavage fluid protein two-dimensional database: study of interstitial lung diseases. Electrophoresis 2000; 21: 2703-2712

10. Sabounchi-Schütt F, Astrom J, Eklund A, Grunewald J, Bjellqvist B. Detection and identification of human bronchoalveolar lavage proteins using narrow-range immobilized $\mathrm{pH}$ gradient DryStrip and the paper bridge sample application method. Electrophoresis 2001; 22: 1851-1860.

11. Sabounchi-Schütt F, Astrom J, Olsson I, Eklund A, Grunewald J, Bjellqvist B. An immobiline DryStrip application method enabling high-capacity two-dimensional gel electrophoresis. Electrophoresis 2000; 21: 3649-3656.

12. Löfgren S, Lundbäck $\mathrm{H}$. The bilateral hilar lymphoma syndrome. Acta Med Scand CXLLI, fasc. IV 1952; 265-273.

13. Eklund A, Blaschke E. Relationship between changed alveolar-capillary permeability and angiotensin converting enzyme activity in serum in sarcoidosis. Thorax 1986; 41: 629-634.

14. Bradford MM. A rapid and sensitive method for the quantitation of microgram quantities of protein utilizing the principle of protein-dye binding. Anal Biochem 1976; 72: 248-254.

15. Heukeshoven J, Dernick R. Improved silver staining procedure for fast staining in PhastSystem Development Unit. I. Staining of sodium dodecyl sulfate gels. Electrophoresis 1988; 9: $28-32$

16. Karas M, Hillenkamp F. Laser desorption ionization of proteins with molecular masses exceeding 10,000 daltons Anal Chem 1988; 60: 2299-2301.

17. Kanamoto T, Hellman U, Heldin $\mathrm{CH}$, Souchelnytskyi S. Functional proteomics of transforming growth factor-beta1stimulated Mv1Lu epithelial cells: Rad51 as a target of TGFbeta1-dependent regulation of DNA repair. Embo $J$ 2002; 21: 1219-1230.

18. Zhang W, Chait BT. ProFound: an expert system for protein identification using mass spectrometric peptide mapping information. Anal Chem 2000; 72: 2482-2489.

19. Lutomski D, Caron M, Cornillot JD, et al. Identification of different galectins by immunoblotting after two-dimensional polyacrylamide get electrophoresis with immobilized $\mathrm{pH}$ gradients. Electrophoresis 1996; 17: 600-606.

20. Golaz O, Hughes GJ, Frutiger S, et al. Plasma and red blood cell protein maps: update 1993. Electrophoresis 1993; 14 1223-1231.

21. Grunewald J, Olerup O, Persson U, Ohrn MB, Wigzell H, Eklund A. T-cell receptor variable region gene usage by CD4+ and CD8+ T cells in bronchoalveolar lavage fluid and peripheral blood of sarcoidosis patients. Proc Natl Acad Sci USA 1994; 91: 4965-4969.

22. Berlin M, Fogdell-Hahn A, Olerup O, Eklund A, Grunewald J. HLA-DR predicts the prognosis in Scandinavian patients with pulmonary sarcoidosis. Am J Respir Crit Care Med 1997; 156: 1601-1605.

23. Costabel U. CD4/CD8 ratios in bronchoalveolar lavage fluid: of value for diagnosing sarcoidosis? Eur Respir J 1997; 10: 2699-2700.

24. Bergmann M, Jonasson S, Klause N, Engler F, Kirsten D, Barth J. Sarcoidosis Analysis of immunoglobulins in sarcoidosis. Vasc Diffuse Lung Dis 1997; 14: 139-145.

25. Kawabata $\mathrm{K}$, Hagio $\mathrm{T}$, Matsumoto $\mathrm{S}$, et al. Delayed neutrophil elastase inhibition prevents subsequent progression of acute lung injury induced by endotoxin inhalation in hamsters. Am J Respir Crit Care Med 2000; 161: 20132018.

26. Suter S, Chevallier I. The effect of Eglin C on the function of human neutrophils in vitro. Biol Chem Hoppe Seyler 1988; 369: 573-578.

27. Shum DK, Chan SC, Ip MS. Neutrophil-mediated degradation of lung proteoglycans: stimulation by tumor necrosis factor-alpha in sputum of patients with bronchiectasis. Am J Respir Crit Care Med 2000; 162: 1925-1931.

28. Jorens PG, Sibille Y, Goulding NJ, et al. Potential role of clara cell protein, an endogenous phospholipase A2 inhibitor, in acute lung injury. Eur Respir J 1995; 8: 16471653.

29. Tsao FH, Meyer KC, Chen X, Rosenthal NS, Hu J. Degradation of annexin I in bronchoalveolar lavage fluid from patients with cystic fibrosis. Am J Respir Cell Mol Biol 1998; 18: 120-128.

30. Ambrose MP, Hunninghake GW. Corticosteroids increase lipocortin $\mathrm{I}$ in BAL fluid from normal individuals and patients with lung disease. J Appl Physiol 1990; 68: 16681671.

31. Smith SF, Tetley TD, Guz A, Flower RJ. Detection of lipocortin 1 in human lung lavage fluid: lipocortin degradation as a possible proteolytic mechanism in the control of inflammatory mediators and inflammation. Environ Health Perspect 1990; 85: 135-144.

32. Vishwanatha JK, Davis RG, Rubinstein I, Floreani A. Annexin I degradation in bronchoalveolar lavage fluids from healthy smokers: a possible mechanism of inflammation. Clin Cancer Res 1998; 4: 2559-2564.

33. El Housni H, Radulescu A, Lecocq R, Dumont JE, Christophe D. Cloning and sequence analysis of human calcyphosine complementary DNA. Biochim Biophys Acta 1997; 1352: 249-252.

34. Wattiez R, Hermans C, Bernard A, Lesur O, Falmagne P Human bronchoalveolar lavage fluid: Two-dimensional gel electrophoresis, amino acid microsequencing and identification of major proteins. Electrophoresis 1999; 20: 1634-1645.

35. Magi B, Bini L, Perari MG, et al. Bronchoalveolar lavage fluid protein composition in patients with sarcoidosis and idiopathic pulmonary fibrosis: A two-dimensional electrophoretic study. Electrophoresis 2002; 23: 3434-3444. 